\title{
Image Steganography using Combined Nearest and Farthest Neighbors Methods
}

\author{
Farhana Sharmin ${ }^{1}$, Muhammad Ibrahim Khan ${ }^{2}$ \\ Department of Computer Science and Engineering \\ Chittagong University of Engineering and Technology, Chattogram, Bangladesh
}

\begin{abstract}
Security is invariably a significant concern during communication. With the ease of communication, there is always a pending threat of intrusion. Steganography is one such way to achieve security by concealing confidential information within a more innocent looking media like image, audio, video etc. In this paper, a new technique is proposed that uses the relationship of a pixel with its Nearest Neighbor and Farthest Neighbor to hide secret information into that pixel. The cover image is divided into2x 2 non-overlapping blocks. According to the vulnerability of the relationship among the pixels, blocks are labelled as Stable and Unstable. The Stable block hides ' $k$ ' secret while unstable block hides ' $n$ ' secret bits. 25 types of different set of ' $k$ ' and ' $n$ ' is examined to evaluate the performance of proposed method. $2 \mathrm{k}$ method is applied to improve the quality of stego image. The experimental result shows that the proposed technique hides a significant number of secret bits with high PSNR. While compared with other existing methods, the proposed method achieves a much higher visual quality than that of those methods.
\end{abstract}

Keywords-Steganography; cryptography; Pixel Value Difference (PVD); image processing; cover image; information security; stego image

\section{INTRODUCTION}

With the progress made in digital technology, information in analog form are being rapidly converted into their digital counterparts. Digital technology and the Internet today offer available cover medias for use in steganography. The frequency of digital image on the Internet makes it the most common option among different cover medias. Internet technology has bridged the global distance between people and organizations by allowing for fast and cheap communication. In areas such as online intellectual property rights, criminal, political and commercial communications there is always a fear of third-party intruder who is seeking access to our communication. It is not enough to rely upon the assumption that communications in today's high-tech world are safe and not being intercepted. Ensuring secure communication is essential. Different tools ensuring secure communication include: hiding the content or nature of communication (encryption, water-marking, steganography), hiding the parties to a communication (anonymity) and conceal a communication that has been taken place (obscurity). A perfect Steganographic system is however an ideal concept. Research in this field aims at increasing capacity, security and robustness of the system. Steganography is a mechanism that implants a secret message into unspectacular cover media to prevent arousing the suspicion of an eavesdropper. The cover media thus serves as a container for the secret information. The outcome is a stego media that appears indistinguishable from the original media and becomes undetectable. In the modern world digital steganography is used for secret communication as well as authentication. A steganographic system consists of two major parts: cover media and stego media. The confidential information that needs to be hidden is embedded in seemingly harmless media. This is the cover media. The result is a stego media that appears identical to the original cover media. Steganography hides information by altering certain characteristics of the cover media that cannot be detected by visual inspection. It makes use of both redundancies that exists in the digital cover media as well as the limitations of the human eye. The design goal of proposed technique is: larger payload and higher PSNR without compromising security.

\section{LITERATURE REVIEW}

Different types of steganographic techniques are proposed to serve different purposes. Original Pixel Value Differencing (PVD) method for gray scale image was proposed by Wu and Tsai in 2003 [1]. Here the cover image is segmented into nonoverlapping blocks consisting two consecutive pixels. The difference values between the pixels are classified into ranges. Based on human vision's tolerance to gray value fluctuation, the interval of 'Range' is decided. Width of the ranges decides the number of secret bits to be hidden in a pixel. Thus, it is an adaptive method. To minimize the exposure of hiding effect of PVD method, Modulus Function (MF) is employed in [2]. In [3], turnover policy and novel adjusting process is employed to improve the performance of method proposed in [2]. Capacity promoting technique is proposed in [4] to increase hiding capacity by finding more edge areas. A new quantization range table, in [5], is designed on the basis of the perfect square number to achieve better image quality and higher capacity. By redefining the remainder function to a more general form, in [6], an indeterminate equation is derived to reduce image distortion. In [7], another steganographic technique is offered by using pixel value differencing on colour images which also ensures that no pixel value in stego image exceeds the range 0 to 255. Where pixel value does not cross the range, the original PVD method is used and elsewhere proposed method has been used for embedding data. Instead of focusing on individual color component, three color components are constituted into two overlapping blocks in [8], where PVD technique is used separately on each block to conceal secret data. In [9], two steganographic technique is proposed based on adaptive quantization range. In first technique, image is divided into $2 \times 2$ non overlapping pixel blocks and second technique divides the image into $3 \times 3$ overlapping pixel blocks. First technique offers 
higher capacity where higher PSNR is achieved by using the second technique which in consequence offers higher security. Smart pixel-adjustment technique is proposed in [10] to reduce visual distortion. Simple LSB substitution method [11] also achieves great image quality by applying Optimal Pixel Adjustment Process (OPAP). To provide greater embedding capacity and less manipulation of image, the side match method [12] exploits correlation between neighboring pixels. It hides secret data depending on the degree of smoothness. Pixel Value Modification (PVM) method [13] uses modulus function to embed secret information in a color image. Combined Pixel Value Differencing and Pixel Indicator Technique [14] is proposed to ensure higher security. Here one channel acts as an indicator where other two channels hold the secret information. Just Noticeable Difference (JND) technique and method of Contrast Sensitivity Function (CSF) is used in [15]. It is an edge detection method that utilizes partial information (3 bits from MSB) of each pixel value. The authors proposed a mathematical method, named $2 \mathrm{k}$ correction, for better imperceptibility. Author in [16] proposed the modified least significanr bits and modulus function with pixel value differencing techniques. Both steganography and cryptography is used in [17] for improved security. A higher quality form of the cover object is utilized in [18]. Author in [19] employed technique based on LSB manipulation and inclusion of redundant noise.

\section{PROPOSED METHOD}

The proposed method can be applied both on gray image and color image. In case of color image, the Red, Green and Blue channels are separated first. Then embedding and extraction algorithm is repeated on all three channels separately. Gray image does not need any pre-processing.

\section{A. Embedding Process}

Step 1: Divide the cover image into $2 \mathrm{X} 2$ non-overlapping blocks consisting four pixels: $\mathrm{P}_{1}, \mathrm{P}_{2}, \mathrm{P}_{3}$ and $\mathrm{P}_{4}$ as shown in Fig. 1.

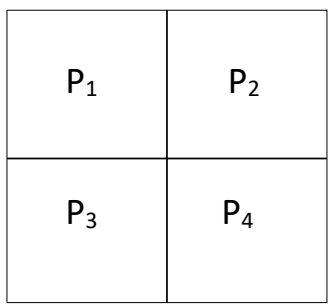

Fig. 1. Cover Image Block.

Step 2: Calculate the distance of $\mathrm{P}_{1}$ with its other neighbor pixels $\mathrm{P}_{2}, \mathrm{P}_{3}$ and $\mathrm{P}_{4}$ by taking the differences as follows:

Difference between $\mathrm{P} 1$ and $\mathrm{P} 2=\mathrm{D} 1=|\mathrm{P} 1-\mathrm{P} 2|$

Difference between P1 and P3 = D2 = |P1 $-\mathrm{P} 3 \mid$

Difference between P1 and P4 = D3 = |P1 $-\mathrm{P} 4 \mid$

Step 3: Determine the Nearest Neighbor (NN) and Farthest Neighbor (FN) of $\mathrm{P}_{1}$. Compare $\mathrm{D}_{1}, \mathrm{D}_{2}$ and $\mathrm{D}_{3}$ calculated in Step 2. The pixel that has the lowest distance from $P_{1}$ is called its Nearest Neighbor and the pixel that has the highest distance from $\mathrm{P}_{1}$ is called its Farthest Neighbor. If $\mathrm{D}_{\mathrm{i}}$ is the lowest distance then $P_{i+1}$ is the nearest neighbor and If $D_{i}$ is the highest distance then $\mathrm{P}_{\mathrm{i}+1}$ is the farthest neighbor, where $\mathrm{i}=1,2,3$.

Step 4: Determine the Range of $\mathrm{P}_{1}$ according to the following four relationship conditions:

Condition 1: If NN $>\mathrm{P}_{1}<\mathrm{FN}$ then

Range $=[0, \min (N N-1, F N-1)]$

Condition 2: If $\mathrm{NN}<\mathrm{P}_{1}>\mathrm{FN}$ then

Range $=[\max (N N+1, F N+1), 255]$

Condition 3: If $\mathrm{NN} \geq \mathrm{P}_{1} \geq \mathrm{FN}$ then

Range $=[F N+1, N N-1]$

Condition 4: If $\mathrm{NN} \leq \mathrm{P}_{1} \leq \mathrm{FN}$ then

Range $=[N N+1, F N-1]$

Step 5: Calculate,

$\mid$ Range $\mid=$ upper limit - lower limit +1

Step 6: Calculate the number of secret bits, $n$, to be hidden into $\mathrm{P}_{1}$.

$\mathrm{n}=\min \left(\right.$ floor $\left(\log _{2}(\mid\right.$ Range $\left.\left.\mid)\right), \mathrm{k}\right)$

where ' $\mathbf{k}$ ' may vary from 1 to 5 . During experiment it is found that the method reaches the maximum capacity at $\mathrm{k}=5$.

Step 7: Take 'n' secret bits from the secret bit stream and convert into its decimal value ' $b$ '.

Step 8: Modify the value of pixel $\mathrm{P}_{1}$ :

$\mathrm{P}_{1}{ }^{\prime}=\mathrm{P}_{1}-\left(\mathrm{P}_{1} \bmod 2^{\mathrm{n}}\right)+\mathrm{b}$

Step 9: To keep the new pixel value $\mathrm{P}_{1}{ }^{\prime}$ nearest to $\mathrm{P}_{1}, 2 \mathrm{k}$ Correction method is applied. The steps are as follows:

Step 9.1: If $\left|\mathrm{P}_{1}{ }^{\prime}-\mathrm{P}_{1}\right|>2^{\mathrm{n}-1}$ then go to Step 9.2. Otherwise $\mathrm{P}_{1}^{\prime}$ remains unchanged. $2^{n}$

Step 9.2: If $\left(\mathrm{P}_{1}{ }^{\prime}-\mathrm{P}_{1}\right)>0$, then $P_{1}{ }^{\prime \prime}=P_{1}{ }^{\prime}-2^{n}$ else $P_{1}{ }^{\prime \prime}=P_{1}{ }^{\prime}+$

Step 10: Check the stability of the relationship among the pixels in the block using Step 2 to Step 4. For correct message extraction, it is required to preserve the same relationship condition it has among the pixels even after hiding secret data. If the relationship among the pixels remains unchanged then the block is labelled as Stable Block and $\mathrm{P}_{1}{ }^{\prime \prime}$ remains unchanged. Otherwise the block is labelled as Unstable Block. In Unstable Block, all four pixels hide 'n' secret data. 'n' may vary from 1 to 5 . For $n>5$, though the hiding capacity increases significantly but PSNR also drops drastically, which leads to vulnerability of the method. For this reason, the value of ' $n$ ' is limited from 1 to 5 . After hiding $\mathrm{n}$ bits, $\mathrm{P}_{1}, \mathrm{P}_{2}, \mathrm{P}_{3}$ and $\mathrm{P}_{4}$ will be changed to $\mathrm{P}_{1}{ }^{\prime}, \mathrm{P}_{2}{ }^{\prime}, \mathrm{P}_{3}{ }^{\prime}$ and $\mathrm{P}_{4}{ }^{\prime}$ as follows:

$\mathrm{P}_{1}^{\prime}=\mathrm{P}_{1}-\left(\mathrm{P}_{1} \bmod 2^{\mathrm{n}}\right)+\mathrm{b}_{1}$

$\mathrm{P}_{2}{ }^{\prime}=\mathrm{P}_{2}-\left(\mathrm{P}_{2} \bmod 2^{\mathrm{n}}\right)+\mathrm{b}_{2}$

$\mathrm{P}_{3}^{\prime}=\mathrm{P}_{3}-\left(\mathrm{P}_{3} \bmod 2^{\mathrm{n}}\right)+\mathrm{b}_{3}$

$\mathrm{P}_{4}^{\prime}=\mathrm{P}_{4}-\left(\mathrm{P}_{4} \bmod 2^{\mathrm{n}}\right)+\mathrm{b}_{4}$ 
Where, $\mathrm{n}$ is the secret binary bits and $\mathrm{b}_{1}, \mathrm{~b}_{2}, \mathrm{~b}_{3}$ and $\mathrm{b}_{4}$ are corresponding decimal values of those secret bits.

To increase security, secret information is embedded in random fashion. Secret message is embedded into stable blocks first then into unstable blocks. In that way, message is hidden in random order instead of sequential order.

For example, in Fig. 2, if 'abcdefghijklmnop' is the secret message, then it is embedded as 'jabkcdlemfgnohpi'. After embedding into all blocks of the cover image, we get the stego image.

\section{B. Extraction Process}

Step 1: Divide the stego image into $2 \mathrm{X} 2$ non overlapping blocks and identify stable blocks (Fig. 3) and unstable blocks (Fig. 4).

In case of stable blocks:

Step 2: Calculate the distance of $\mathrm{P}_{1}{ }^{\prime}$ with $\mathrm{P}_{2}, \mathrm{P}_{3}$ and $\mathrm{P}_{4}$.

Difference between $\mathrm{P}_{1}{ }^{\prime}$ and $\mathrm{P}_{2}=D_{1}{ }^{\prime}=\left|P_{1}{ }^{\prime}-P_{2}\right|$

Difference between $\mathrm{P}_{1}{ }^{\prime}$ and $\mathrm{P}_{3}=D_{2}{ }^{\prime}=\left|P_{1}{ }^{\prime}-P_{3}\right|$

Difference between $\mathrm{P}_{1}{ }^{\prime}$ and $\mathrm{P}_{4}=D_{3}{ }^{\prime}=\left|P_{1}{ }^{\prime}-P_{4}\right|$

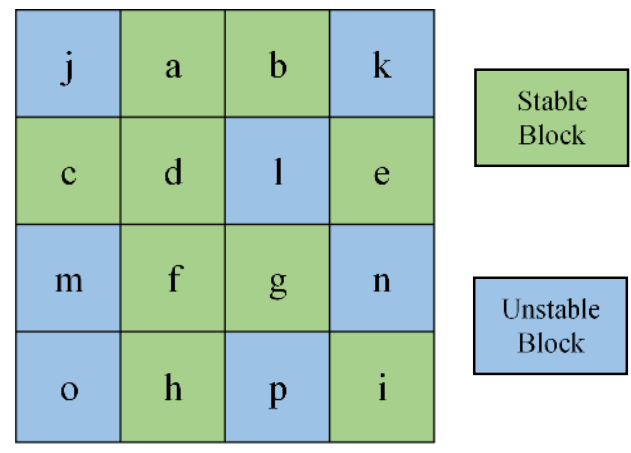

Fig. 2. Embedding Secret Message in Random Order.

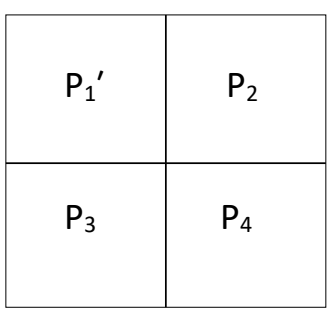

Fig. 3. Stable Block.

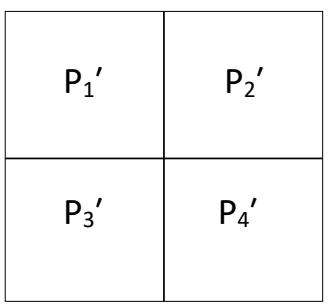

Fig. 4. Unstable Block.
Step 3: Determine the Nearest Neighbor (NN) and Farthest Neighbor $(\mathrm{FN})$ of $\mathrm{P}_{1}{ }^{\prime}$ same as described in Step 3 of embedding process.

Step 4: Determine the Range of $\mathrm{P}_{1}{ }^{\prime}$ according to the four relationship conditions specified in Step 4 of embedding process.

Step 5: Calculate, $\mid$ Range $\mid=$ upper limit -lower limit +1

Step 6: Calculate the number of secret bits ' $n$ ' to be extracted from $\mathrm{P}_{1}^{\prime}$.

$\mathrm{n}=\min \left(\right.$ floor $\left(\log _{2}(\mid\right.$ Range $\left.\left.\mid)\right), \mathrm{k}\right)$

Step 7: Extract $\mathbf{n}$ secret bits from the stego pixel $\mathrm{P}_{1}{ }^{\prime}$. $\mathrm{b}=\mathrm{P}_{1}{ }^{\prime} \bmod 2^{\mathrm{n}}$

Step 8: Convert the decimal value b into its corresponding binary value. Obtained binary bits are the secret bits.

In case of Unstable Block, secret message is extracted from all four pixels using following equations:

$$
\begin{aligned}
& P S N R=10 \log _{10}\left(\frac{M A X I^{2}}{M S E}\right) \\
& M S E=\frac{1}{\mathrm{~cm} \mathrm{n}} \sum_{i=0}^{m-1} \sum_{j=0}^{n-1}[I(i, j)-K(i, j)]^{2} \\
& \mathrm{~b}_{1}=\mathrm{P}_{1}{ }^{\prime} \bmod 2^{\mathrm{n}} \\
& \mathrm{b}_{2}=\mathrm{P}_{2}{ }^{\prime} \bmod 2^{\mathrm{n}} \\
& \mathrm{b}_{3}=\mathrm{P}_{3}{ }^{\prime} \bmod 2^{\mathrm{n}} \\
& \mathrm{b}_{4}=\mathrm{P}_{4}{ }^{\prime} \bmod 2^{\mathrm{n}}
\end{aligned}
$$

By converting $b_{1}, b_{2}, b_{3}$ and $b_{4}$ into their corresponding binary value, we get the secret bits hidden into the pixels.

\section{EXPERIMENTAL RESULTS}

Most widely used 512X512X3 color images (Lena, Baboon, Pepper, Jet, Sailboat, House, Splash, Tiffany etc.) and 512X512 gray images (Lena, Boat, Baboon, Tank, Pepper, Tiffany, Jet, Elaine, Barbara, etc.) are used to conceal the secret information. In order to assess the efficiency of proposed method, two parameters are employed: Capacity and Peak Signal to Noise Ratio (PSNR). Capacity is the maximum number of secret bits an image can hide. Peak Signal to Noise Ratio (PSNR) quantifies the quality of stego image.

Here, MSE calculates the Mean Squared Error. I and K are cover and stego image respectively where both have $\mathrm{m}$ rows and $n$ columns, $\mathrm{c}$ is the number of channels of the image. $\mathrm{MAX}_{\mathrm{I}}$ is the maximum pixel value of cover image. Higher PSNR indicates better image quality. Usually, when the PSNR is greater than $30 \mathrm{~dB}$, Human Visual System (HVS) is unable to detect the changes made in an image [20]. 
In steganography, capacity and PSNR walk in reverse way. The more the capacity, usually the lower is the PSNR. Lower PSNR leads to vulnerability of a method. In our proposed method, ' $\mathrm{k}$ ' and ' $\mathrm{n}$ ' play a major role to control the capacity.

As for example, Table I (color image) and Table II (gray image) depict how capacity (in bits) as well as PSNR (in db) varies for different values of ' $k$ ' and ' $\mathbf{n}$ ' for image Lena. Users can choose any set of $(k, n)$ to meet their priority requirement.

Taking $30 \mathrm{db}$ as the threshold level PSNR, Table III and Table IV depicts the highest capacity with threshold level PSNR and capacity with highest PSNR for color images and gray images respectively. Capacity is measured in bits and PSNR is measured in db. From the experimental results, we can see that the proposed method can hide a large amount of secret information yet keeping a high PSNR.

Fig. 5 shows some color images and their corresponding stego images where some gray images and their respective stego images are shown in Fig. 6. However, it is also clear from the figures that it is evident that Human Visual System (HVS) does not perceive distortion.

TABLE. I. CAPACITY AND PSNR OF COLOR IMAGE LENA FOR DIFFERENT VALUES OF ' $\mathrm{K}$ ' AND ' $\mathrm{N}$ '

\begin{tabular}{|c|c|c|}
\hline Type of $(k, n)$ & Capacity & PSNR \\
\hline Type $1(1,1)$ & 742866 & 56.20 \\
\hline Type $2(1,2)$ & 1471202 & 51.45 \\
\hline Type $3(1,3)$ & 2199538 & 45.83 \\
\hline Type $4(1,4)$ & 2927874 & 39.85 \\
\hline Type $5(1,5)$ & 3470530 & 34.13 \\
\hline Type $6(2,1)$ & 712671 & 56.40 \\
\hline Type $7(2,2)$ & 1380255 & 51.76 \\
\hline Type $8(2,3)$ & 2047839 & 46.18 \\
\hline Type $9(2,4)$ & 2715423 & 40.22 \\
\hline Type $10(2,5)$ & 3381967 & 34.28 \\
\hline Type $11(3,1)$ & 702121 & 56.23 \\
\hline Type $12(3,2)$ & 1326941 & 51.88 \\
\hline Type $13(3,3)$ & 1951761 & 46.42 \\
\hline Type $14(3,4)$ & 2576581 & 40.50 \\
\hline Type $15(3,5)$ & 3201401 & 34.57 \\
\hline Type $16(4,1)$ & 702444 & 50.43 \\
\hline Type $17(4,2)$ & 1058920 & 49.44 \\
\hline Type $18(4,3)$ & 1415396 & 46.83 \\
\hline Type $19(4,4)$ & 1771872 & 42.29 \\
\hline Type $20(4,5)$ & 2128348 & 36.83 \\
\hline Type $21(5,1)$ & 702612 & 55.46 \\
\hline Type $22(5,2)$ & 1303484 & 51.69 \\
\hline Type $23(5,3)$ & 1904356 & 46.48 \\
\hline Type $24(5,4)$ & 2505228 & 40.63 \\
\hline Type $25(5,5)$ & 3106100 & 34.73 \\
\hline
\end{tabular}

TABLE. II. CAPACITY AND PSNR OF GRAY IMAGE LENA FOR DIFFERENT VALUES OF 'K' AND ' $N$ '

\begin{tabular}{|c|c|c|}
\hline Type of $(k, n)$ & Capacity & PSNR \\
\hline Type $1(1,1)$ & 242106 & 51.55 \\
\hline Type $2(1,2)$ & 477530 & 46.82 \\
\hline Type $3(1,3)$ & 712954 & 41.19 \\
\hline Type $4(1,4)$ & 948378 & 35.22 \\
\hline Type $5(1,5)$ & 1158682 & 29.39 \\
\hline Type $6(2,1)$ & 232365 & 51.74 \\
\hline Type $7(2,2)$ & 448009 & 47.11 \\
\hline Type $8(2,3)$ & 663653 & 41.55 \\
\hline Type $9(2,4)$ & 879297 & 35.60 \\
\hline Type $10(2,5)$ & 1094941 & 29.68 \\
\hline Type $11(3,1)$ & 229963 & 51.65 \\
\hline Type $12(3,2)$ & 435735 & 47.22 \\
\hline Type $13(3,3)$ & 641507 & 41.73 \\
\hline Type $14(3,4)$ & 847279 & 35.79 \\
\hline Type $15(3,5)$ & 1053051 & 29.89 \\
\hline Type $16(4,1)$ & 230056 & 45.95 \\
\hline Type $17(4,2)$ & 351460 & 44.87 \\
\hline Type $18(4,3)$ & 472864 & 42.13 \\
\hline Type $19(4,4)$ & 594268 & 37.51 \\
\hline Type $20(4,5)$ & 715672 & 32.03 \\
\hline Type $21(5,1)$ & 229831 & 51.26 \\
\hline Type $22(5,2)$ & 430735 & 47.12 \\
\hline Type $23(5,3)$ & 631639 & 41.78 \\
\hline Type $24(5,4)$ & 832543 & 35.89 \\
\hline Type $25(5,5)$ & 1033447 & 29.98 \\
\hline
\end{tabular}

TABLE. III. CAPACITY AND PSNR FOR PROPOSED METHOD (COLOR IMAGE)

\begin{tabular}{|l|l|l|l|l|}
\hline $\begin{array}{l}\text { Cover Image } \\
(512 \times \text { x12 x 3) }\end{array}$ & \multicolumn{3}{|l|}{$\begin{array}{l}\text { Highest Capacity with } \\
\text { threshold level PSNR }\end{array}$} & \multicolumn{2}{l|}{$\begin{array}{l}\text { Capacity with highest } \\
\text { PSNR }\end{array}$} \\
\hline \multirow{2}{*}{ Lena } & Capacity & PSNR & Capacity & PSNR \\
\cline { 2 - 5 } & 3470530 & 34.13 & 712671 & 56.40 \\
\hline Baboon & 3490302 & 34.14 & 768667 & 56.03 \\
\hline Pepper & 3474527 & 34.28 & 730659 & 56.25 \\
\hline Sailboat & 3481380 & 34.18 & 745340 & 56.17 \\
\hline Car house & 3475411 & 34.19 & 708470 & 56.46 \\
\hline Splash & 3321788 & 34.21 & 669662 & 56.75 \\
\hline Jet & 3424467 & 34.33 & 684031 & 56.64 \\
\hline Tiffany & 3471557 & 34.64 & 710055 & 56.40 \\
\hline
\end{tabular}


TABLE. IV. CAPACITY AND PSNR FOR PROPOSED METHOD (GRAY IMAGE)

\begin{tabular}{|l|l|l|l|l|}
\hline $\begin{array}{l}\text { Cover Image } \\
\text { (512 x 512) }\end{array}$ & \multicolumn{3}{|l|}{$\begin{array}{l}\text { Highest Capacity with } \\
\text { threshold level PSNR }\end{array}$} & \multicolumn{2}{l|}{$\begin{array}{l}\text { Capacity with highest } \\
\text { PSNR }\end{array}$} \\
\hline \multirow{2}{*}{ Lena } & Capacity & PSNR & Capacity & PSNR \\
\cline { 2 - 5 } & 948378 & 35.22 & 232365 & 51.74 \\
\hline Baboon & 1013763 & 34.97 & 249900 & 51.36 \\
\hline Pepper & 1038439 & 30.01 & 237555 & 51.62 \\
\hline Jet & 1038254 & 30.00 & 226950 & 51.91 \\
\hline Airplane & 910753 & 30.74 & 191549 & 52.74 \\
\hline Boat & 1002498 & 35.02 & 244560 & 51.47 \\
\hline Lake & 998313 & 35.04 & 244987 & 51.48 \\
\hline Tiffany & 1017169 & 30.11 & 228397 & 51.83 \\
\hline Elaine & 1010298 & 34.96 & 247009 & 51.43 \\
\hline Goldhill & 994878 & 35.08 & 242765 & 51.52 \\
\hline Cameraman & 1018789 & 30.05 & 217845 & 52.16 \\
\hline Carhouse & 932328 & 35.30 & 233172 & 51.75 \\
\hline Tank & 1047990 & 30.00 & 242889 & 51.49 \\
\hline Truck & 980733 & 35.16 & 238737 & 51.60 \\
\hline Couple & 985443 & 35.08 & 240799 & 51.53 \\
\hline Zelda & 1027092 & 30.00 & 230426 & 51.77 \\
\hline Barbara & 979443 & 35.09 & 241677 & 51.54 \\
\hline
\end{tabular}

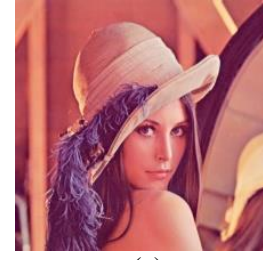

(a)

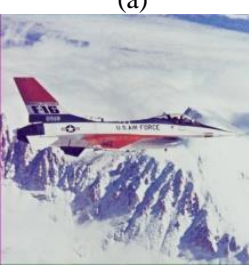

(d)

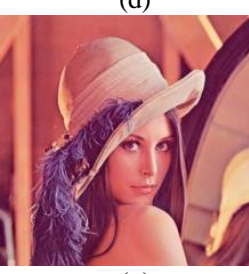

$(\mathrm{g})$

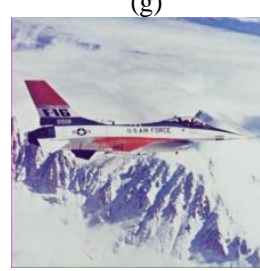

(j)

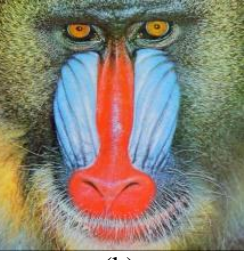

(b)

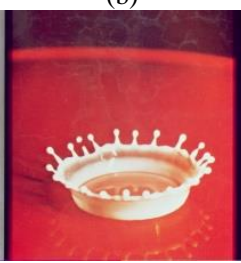

(e)

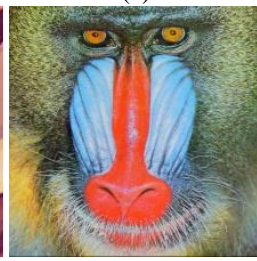

(h)

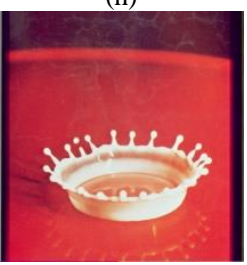

(k)

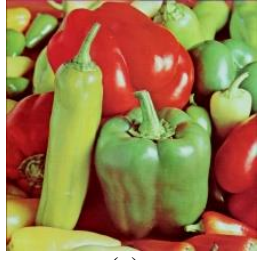

(c)
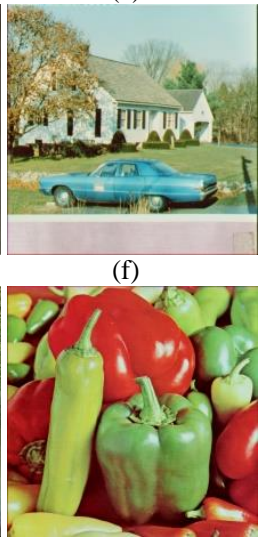

(i)

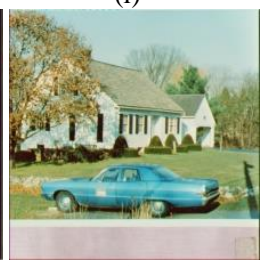

(1)
Fig. 5. Color Cover Images: (a) Lena (b) Baboon (c) Peppers (d) Jet (e) Splash (f) Carhouse and (g) - (l) are their Respective Stego Images for Type $18(\mathrm{k}=4, \mathrm{n}=3)$.

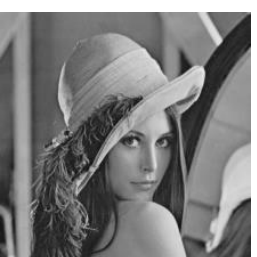

(a)

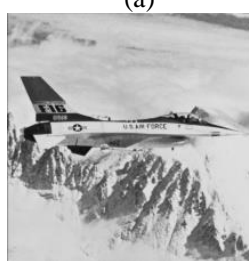

(d)

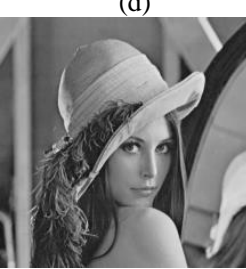

(g)

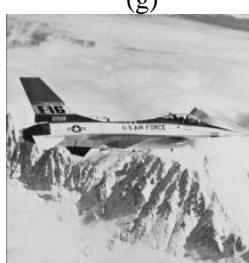

(j)

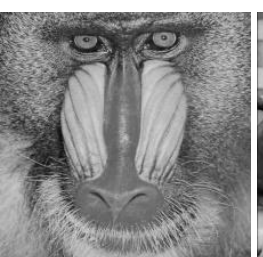

(b)

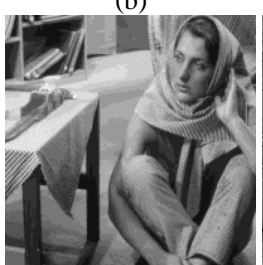

(e)

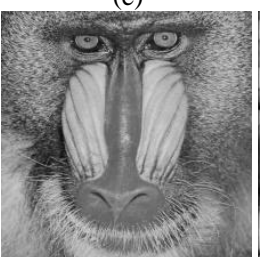

(h)

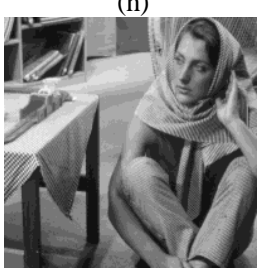

(k)

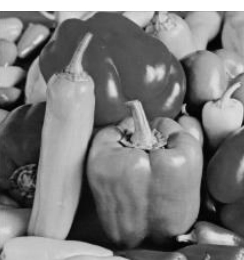

(c)

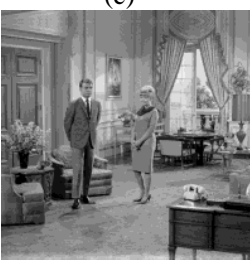

(f)

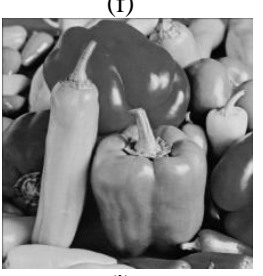

(i)

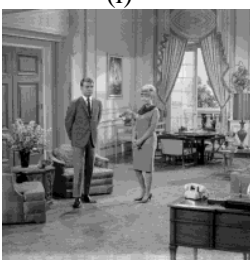

(1)
Fig. 6. Gray Cover Images: (a) Lena (b) Baboon (c) Peppers (d) Jet (e) Splash (f) Carhouse and (g) - (l) are their Respective Stego Images for Type $18(\mathrm{k}=4, \mathrm{n}=3)$.

\section{COMPARATIVE ANALYSIS AND DISCUSSION}

To analyse how well the proposed method is working, it is compared to some relevant methods proposed before like $\mathrm{Wu}$ and Tsai's method [1], Joo et al.'s method [3], Yang et al.'s method [4], Tseng and Leng's method [5], Mandal and Das's method [7], Prasad and Pal's method [8], Swain's method [9] and Yang and Wang's method [10]. In order to have a comparative analysis of the outcomes of proposed method, Table V and Table VI is constructed to show the comparison between proposed method and other existing methods for color image and gray image respectively. For each existing method, PSNR at the highest capacity is compared with the PSNR of proposed method at the same capacity. From Table V and Table VI, it is evident that proposed method outperformed the existing methods each time. For same capacity, proposed method's PSNR is significantly higher than other methods compared. In case of color image, proposed method's average PSNR is $26.43 \%, 49.21 \%, 11.02 \%$ and $41.32 \%$ higher than that of Mandal and Das's method, Yang and Wang's method, Swain's method and Prasad \& Pal's method, respectively. Applying the proposed method on gray images also produces better result than other methods compared. Here also, for same capacity, proposed method's average PSNR is $16.29 \%, 3.50 \%$, $16.94 \%$ and $12.81 \%$ higher than the PSNR gained in $\mathrm{Wu} \&$ Tsai's method, Tseng et al.'s method, Yang et al.'s method and Joo et al.'s methods, respectively. 
TABLE. V. COMPARISON BETWEen PREVIOUS METHOdS AND PROPOSED METHOD FOR COLOR IMAgES

\begin{tabular}{|c|c|c|c|c|c|c|c|c|c|c|c|c|}
\hline \multirow[t]{2}{*}{$\begin{array}{l}\text { Cover Image } \\
(512 \text { x } 512 \text { x } 3)\end{array}$} & \multicolumn{2}{|c|}{$\begin{array}{l}\text { Mandal and } \\
\text { Das's method }\end{array}$} & \multirow{2}{*}{$\begin{array}{l}\begin{array}{l}\text { Proposed } \\
\text { method }\end{array} \\
\text { PSNR }\end{array}$} & \multicolumn{2}{|c|}{$\begin{array}{l}\text { Yang and } \\
\text { Wang's method }\end{array}$} & \multirow{2}{*}{$\begin{array}{l}\text { Proposed } \\
\text { method }\end{array}$} & \multicolumn{2}{|c|}{ Swain's method } & \multirow{2}{*}{$\begin{array}{l}\begin{array}{l}\text { Proposed } \\
\text { method }\end{array} \\
\text { PSNR }\end{array}$} & \multicolumn{2}{|c|}{$\begin{array}{l}\text { Prasad and Pal's } \\
\text { method }\end{array}$} & \multirow{2}{*}{ 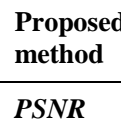 } \\
\hline & Capacity & PSNR & & Capacity & PSNR & & Capacity & PSNR & & Capacity & PSNR & \\
\hline Lena & 1166296 & 42.26 & 52.45 & 196608 & 41.58 & 62.14 & 1341192 & 46.17 & 51.89 & 1976671 & 31.01 & 46.34 \\
\hline Baboon & 1159328 & 38.44 & 52.43 & 196608 & 33.29 & 61.96 & 1489945 & 48.49 & 51.38 & 2219715 & 32.29 & 45.79 \\
\hline Peppers & 1167960 & 42.28 & 52.42 & 196608 & 39.43 & 62.01 & 1350251 & 47.06 & 51.81 & 1783210 & 30.10 & 46.81 \\
\hline Jet & 1165184 & 42.60 & 52.51 & 196608 & 43.73 & 62.35 & 1267690 & 46.18 & 52.14 & 1753707 & 35.66 & 46.88 \\
\hline Sailboat & 1146224 & 40.66 & 52.48 & 196608 & 47.41 & 62.04 & 1424967 & 47.29 & 51.59 & 2130772 & 33.11 & 46.16 \\
\hline Car-House & 1162992 & 41.41 & 52.49 & 196608 & 41.34 & 62.26 & 1339985 & 44.73 & 51.90 & 2079088 & 34.59 & 46.08 \\
\hline Splash & 1173856 & 42.86 & 52.52 & 196608 & 44.86 & 62.39 & - & - & - & - & - & - \\
\hline
\end{tabular}

TABLE. VI. COMPARISON BETWEen PREVIOUs Methods AND Proposed METHOD FOR GRAy IMAgES

\begin{tabular}{|c|c|c|c|c|c|c|c|c|c|c|c|c|}
\hline \multirow[t]{2}{*}{$\begin{array}{l}\text { Cover Image } \\
(512 \times 512)\end{array}$} & \multicolumn{2}{|c|}{ Wu and Tsai's method } & \multirow{2}{*}{$\begin{array}{l}\text { Proposed } \\
\text { Method }\end{array}$} & \multicolumn{2}{|c|}{$\begin{array}{l}\text { Tseng et al. } \\
\text { method }\end{array}$} & \multirow{2}{*}{$\begin{array}{l}\text { Proposed } \\
\text { Method } \\
\text { PSNR }\end{array}$} & \multicolumn{2}{|c|}{$\begin{array}{l}\text { Yang et al. } \\
\text { method }\end{array}$} & \multirow{2}{*}{$\begin{array}{l}\text { Proposed } \\
\text { Method } \\
\text { PSNR }\end{array}$} & \multicolumn{2}{|c|}{ Joo et al. Method } & \multirow{2}{*}{$\begin{array}{l}\text { Proposed } \\
\text { Method }\end{array}$} \\
\hline & Capacity & PSNR & & Capacity & PSNR & & Capacity & PSNR & & Capacity & PSNR & \\
\hline Lena & 407680 & 41.79 & 47.51 & 215740 & 50.70 & 52.07 & 528966 & 36.75 & 42.56 & 407152 & 43.4 & 47.52 \\
\hline Baboon & 450328 & 37.90 & 47.04 & 241719 & 48.57 & 51.50 & 559222 & 34.30 & 42.22 & 456344 & 39.2 & 46.98 \\
\hline Jet & 409944 & 40.97 & 47.52 & 204682 & 50.89 & 52.37 & - & - & - & 409768 & 42.8 & 47.52 \\
\hline Peppers & 405480 & 41.73 & 47.50 & 217290 & 50.57 & 52.01 & 528791 & 36.83 & 42.54 & 406520 & 42.5 & 47.49 \\
\hline Elaine & 407128 & 42.1 & 47.44 & - & - & - & - & - & - & 407144 & 43.5 & 47.44 \\
\hline Tiffany & 403764 & 41.47 & 47.53 & 210935 & 50.86 & 52.18 & 528678 & 36.35 & 42.49 & - & - & - \\
\hline Boat & 418560 & 39.6 & 47.29 & - & - & - & - & - & - & 419920 & 41.0 & 47.27 \\
\hline Tank & 403990 & 42.3 & 47.33 & - & - & - & - & - & - & - & - & - \\
\hline Lake & 420912 & 40.0 & 47.34 & 224915 & 49.86 & 51.85 & 535984 & 36.51 & 42.41 & 421296 & 41.5 & 47.34 \\
\hline Gold hill & 405634 & 42.20 & 47.48 & - & - & - & 529319 & 37.15 & 42.51 & - & - & - \\
\hline Zelda & 398584 & 42.66 & 47.63 & - & - & - & 526145 & 37.78 & 42.60 & - & - & - \\
\hline Barbara & 442529 & 36.24 & 47.12 & - & - & - & 548206 & 34.80 & 42.33 & - & - & - \\
\hline
\end{tabular}

\section{CONCLUSION}

An efficient technique is introduced to hide a significant amount of secret information keeping the distortion unnoticeable. Capacity and PSNR is quite higher than other existing methods discussed. The greatest advantage of our proposed method is, users can easily tailor this method according to their need by taking the desired Type of $(k, n)$. Either to achieve higher capacity or to maintain a higher PSNR, whatever the target may be, just tuning the values of ' $\mathrm{k}$ ' and ' $n$ ' is sufficient. Random embedding order is followed instead of traditional sequential order by hiding secret information into Stable Blocks first than into Unstable Blocks. This step is working as an extra layer of security if any unauthorized attack happens. Since only the sender and recipient know the correct order of extraction, the intruder is supposed to get a meaningless message in that case. Future work may include utilizing the unstable blocks in different way like hiding variable rate secret data instead of fixed ' $n$ ' bits secret data.

\section{REFERENCES}

[1] D.-C. Wu and W.-H. Tsai, "A steganographic method for images by pixel-value differencing," Pattern Recognition Letters, vol. 24, no. 9-10, pp. 1613-1626, 2003.
[2] C. Wang, N. Wu, C. Tsai and M. Hwang, "A high quality steganographic method with pixel-value differencing and modulus function", Journal of Systems and Software, vol. 81, no. 1, pp. 150-158, 2008.

[3] J. Joo, H. Lee and H. Lee, "Improved Steganographic Method Preserving Pixel-Value Differencing Histogram with Modulus Function", EURASIP Journal on Advances in Signal Processing, vol. 2010, no. 1, 2010.

[4] C. Yang, C. Weng, H. Tso and S. Wang, "A data hiding scheme using the varieties of pixel-value differencing in multimedia images", Journal of Systems and Software, vol. 84, no. 4, pp. 669-678, 2011.

[5] H.-W. Tseng and H.-S. Leng, "A Steganographic Method Based on Pixel-Value Differencing and the Perfect Square Number," Journal of Applied Mathematics, vol. 2013, pp. 1-8, 2013.

[6] W. Zhao, Z. Jie, L. Xin, and W. Qiaoyan, "Data embedding based on pixel value differencing and modulus function using indeterminate equation," The Journal of China Universities of Posts and Telecommunications, vol. 22, no. 1, pp. 95-100, 2015.

[7] J. K. Mandal and D. Das, "Colour Image Steganography based on Pixel Value Differencing in Spatial Domain," IJIST International Journal of Information Sciences and Techniques, vol. 2, no. 4, pp. 83-93, 2012.

[8] S. Prasad and A. Pal, "An RGB colour image steganography scheme using overlapping block-based pixel-value differencing", Royal Society Open Science, vol. 4, no. 4, p. 161066, 2017.G. Swain, "Adaptive pixel value differencing steganography using both vertical and horizontal edges", Multimedia Tools and Applications, vol. 75, no. 21, pp. 1354113556,2015 
[9] C.-Y. Yang and W.-F. Wang, "Block-Based Colour Image Steganography Using Smart Pixel-Adjustment," Advances in Intelligent Systems and Computing Genetic and Evolutionary Computing, pp. 145$154,2015$.

[10] C.-K. Chan and L. Cheng, "Hiding data in images by simple LSB substitution," Pattern Recognition, vol. 37, no. 3, pp. 469-474, 2004.

[11] C.-C. Chang and H.-W. Tseng, "A steganographic method for digital images using side match," Pattern Recognition Letters, vol. 25, no. 12, pp. 1431-1437, 2004.

[12] V. Nagaraj, V. Vijayalakshmi, and G. Zayaraz, "Color Image Steganography based on Pixel Value Modification Method Using Modulus Function," IERI Procedia, vol. 4, pp. 17-24, 2013.

[13] M. G. Gouthamanaath and A. Kangaiammal, "Color Image Steganography using Combined Pixel Value Differencing and Pixel Indicator Technique in Spatial Domain," IJCA Proceedings on National Conference on Research Issues in Image Analysis and Mining Intelligence, pp. 20-23, Jun. 2015.

[14] J.-G. Yu, E.-J. Yoon, S.-H. Shin, and K.-Y. Yoo, "A New Image Steganography Based on 2k Correction and Edge-Detection," Fifth International Conference on Information Technology: New Generations (itng 2008), 2008.
[15] T.-S. Chen, C.-C. Chang, and M.-S. Hwang, "A virtual image cryptosystem based upon vector quantization," IEEE Transactions on Image Processing, vol. 7, no. 10, pp. 1485-1488, Oct. 1998.

[16] M. Sabokdast and M. Mohammadi, "A steganographic method for images with modulus function and modified LSB replacement based on PVD," The 5th Conference on Information and Knowledge Technology, 2013 .

[17] S. Gupta, A. Goyal, and B. Bhushan, "Information Hiding Using Least Significant Bit Steganography and Cryptography," IJMECS International Journal of Modern Education and Computer Science, vol. 4, no. 6, pp. 27-34, 2012.

[18] T. Denemark and J. Fridrich, "Side-informed steganography with additive distortion," 2015 IEEE International Workshop on Information Forensics and Security (WIFS), 2015.

[19] Chadha A., Satam N., Sood R., and Bade D., "An Efficient Method for Image and Audio Steganography using Least Significant Bit Substitution," International Journal of Computer Applications, vol. 77, no. 13, pp. 37-45, 2013.

[20] M. Hussain and M. Hussain, "A Survey of Image Steganography Techniques," International Journal of Advanced Science and Technology, vol. Vol. 54, pp. 113-124, May 2013. 